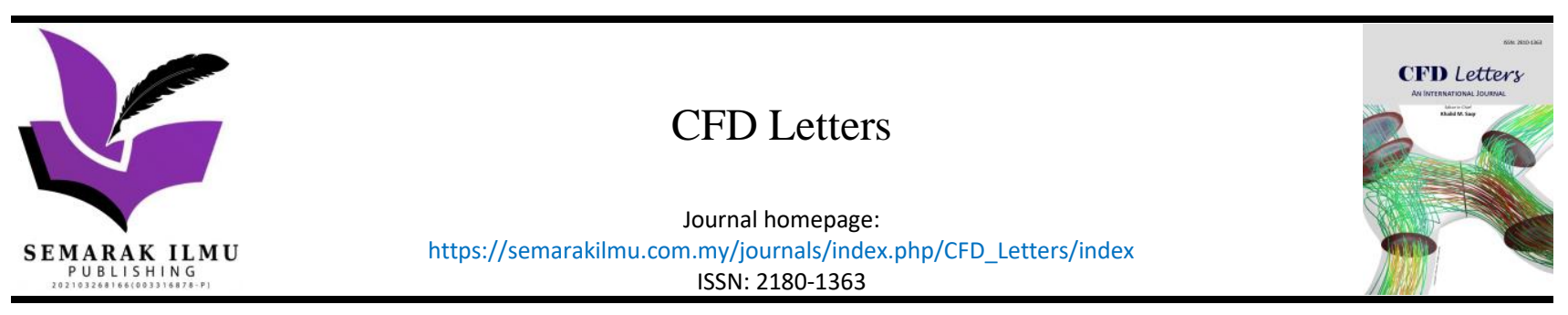

\title{
Effect of Ribs as Passive Control on Base Pressure at Sonic Mach Numbers
}

\author{
Ambareen Khan $^{1}$, Nurul Musfirah Mazlan ${ }^{1,}{ }^{*}$, Ervin Sulaeman ${ }^{2}$ \\ School of Aerospace Engineering, Engineering Campus, Universiti Sains Malaysia, 14300 Nibong Tebal, Pulau Pinang, Malaysia \\ Mechanical Engineering Dept., Faculty of Engineering, IIUM, Kuala Lumpur, Malaysia
}

ARTICLE INFO

\section{Article history:}

Received 14 August 2021

Received in revised form 8 September 2021

Accepted 9 September 2021

Available online 9 January 2022

\section{Keywords:}

Passive control; rib's size; base pressure; velocity; sonic flow

\section{ABSTRACT}

Passive control is a method used to control the base pressure of the convergentdivergent nozzle for high speed vehicles. The passive control contributes significant reduction of base pressure which mainly depending on many factors such as number of ribs, flow Mach number and rib's size. The flow behaviour inside the nozzle at the respected factors still unknown. Therefore, this study aims to assess the effect of ribs in a suddenly expanded flow to control the base pressure at sonic Mach numbers. The study is performed using ANSYS Fluent. The flow expands in a duct with $18 \mathrm{~mm}$ diameter and $108 \mathrm{~mm}$ length. The ribs have aspect ratios of 3:1 to 3:3 which were fixed to the duct circumferentially. The position of the rib varies from 1D (duct diameter) to 4D and having different aspect ratios. The level of expansion varies from 1.5 to 5 while the rib is fixed at a 3:3 aspect ratio. The variation of pressure and velocity contours of the flow inside the nozzle are presented. The simulation analysis indicates that the flow expansion with the presence of ribs considerably improves the base pressure. It is concluded that at the flow with sonic Mach number, the rib with a 3:3 aspect ratio located at 4D has shown the highest improvement in base pressure.

\section{Introduction}

Sudden increases flow phenomena in a nozzle can be found in high speed vehicles. When the flow is exiting from the nozzle, the separating shear layer is bifurcated in two regions, namely, the central flow region and the recirculation region. The pressure in the recirculation zone is lower than the atmospheric pressure. Owing to this low pressure, the base drag component increases considerably. The base drag component is as high as $70 \%$ of the net drag, as indicated by the literature [1-3]. Once the flow stream expands in a nozzle, the shear layer from the nozzle exit is primarily divided and later connects the flow with the duct surface at a finite gap, as shown in Figure 1. The distance from the exit of the flow accelerating device to flow is reattached is famously known as reattachment length $[4,5]$.

\footnotetext{
* Corresponding author.

E-mail address: nmusfirah@usm.my (Nurul Musfirah Mazlan)
} 


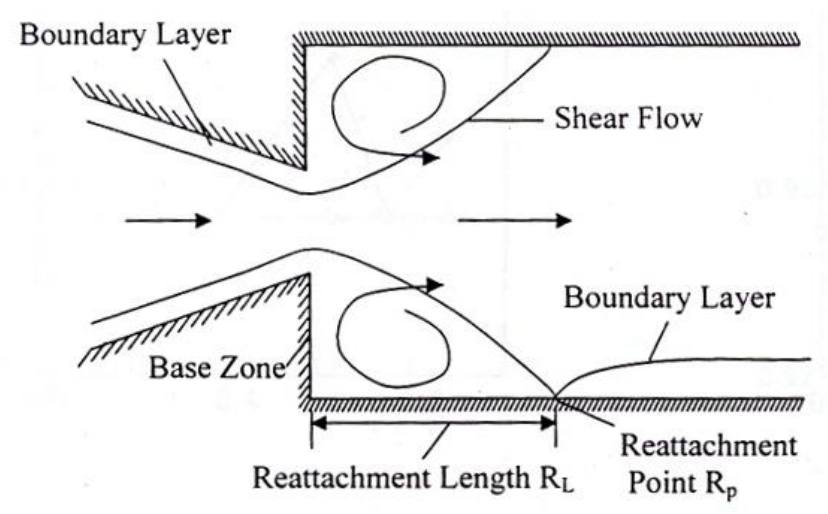

Fig. 1. Sudden expansion flow field [3]

The literature indicates that the investigation was performed on various parameters to study the velocity and thrust of suddenly expanded flows by Pathan et al., [6-8]. A significant rise in pressure occurred at the recirculation region for favourable and adverse pressure gradients without disregarding the wall pressure. Pathan et al., [8] examined the suddenly expanded flows numerically and found that internal and external flow studies are principally the same. Vikramaditya et al., [9] investigated the instability at the missile base at $M=0.7$ with and without a cavity. The wind tunnel was conducted for different angles in azimuth due to cavities that enhanced base pressure and lowered oscillations in a duct. On the basis of the Strouhal number, the cavity demonstrated narrowband sounds of three kinds, as found from the spectra. Quadros et al., [10] and Pathan et al., [11] examined the various studies for base pressure management for a CD nozzle and the efficacy of tiny jets.

Chaudhary et al., [12] investigated the effect of the pressure at the base of the CD nozzle and the efficacy of the flow regulators to regulate base pressure with an abrupt increase. Four tiny jets with a $0.5 \mathrm{~mm}$ radius situated at $90^{\circ}$ at a PCD of $13 \mathrm{~mm}$ were experimentally investigated. The microjets' effectiveness at various expansion levels was used to manage the base pressure for ducts with an abrupt rise in area. The results show an extreme rise in base pressure of more than $100 \%$ at Mach 2.58, and flow controls do not adversely influence the pressure inside the duct.

Additionally, the flow controllers can act as efficient regulators boosting the base pressure values to nearly equal ambient pressure $[13,14]$. Flow from CD nozzles connected to a circular tube with a higher area than the nozzle exit area was investigated with a significant focus on the base pressure efficacy and quality of the flow in the tube. Rehman and Khan [15] experimented an internal highspeed flows from a CD flow accelerating device. They found that tiny jets do not negatively affect the outcomes of static pressure. The inertia levels were from 1.25 to 3.0 and $L=10 D$ to $1 D$. The nozzles producing these Mach values were conducted for NPR 3 to 11. The static duct pressure is not adversely affected by the flow control mechanism. The effect of Mach number on the flow pattern in the suddenly expanded duct was studied in Rathakrishnan [16] and Khan and Rathakrishnan [17], in which despite the nozzles, the flow control effects in a rise in pressure at Mach 2.58 for duct sizes 6D and 10D were found to be over-expanded. The attainment of ambient pressure is moved further upstream for a duct size of 10D.

The numerical turbulence model of high-speed flows from a nozzle into the duct is important to be studied in order to understand the effect of control method on the base pressure. This motivation has led to developing a computational model of converging nozzles and ducts. Rathakrishnan [16] addressed the problem of base pressure control in a converging nozzle using five ribs. In the present study, we addressed the same problem using a single rib, producing better results and thereby 
reducing the friction coefficient and overall weight of aerospace vehicles. The variation in base pressure and control effectiveness due to annular ribs is studied numerically using the k- $\varepsilon$ model.

Rathakrishnan [16] used five ribs at 1-D locations to control the base pressure. They arrived at a 3:1 rib configuration that resulted in minimum base pressure. However, when the increased rib height was tested, a marginal increase in base pressure was found. The present study proposes using a single rib instead of multiple ribs to reduce the system's weight and simultaneously decrease the skin friction drag. Furthermore, we propose a lower area ratio that seems to be more beneficial than the higher ratio of the duct. Results indicate that when the area ratio is 6.25 , a continuous decrease in the base pressure occurred even though the nozzles were operated under the influence of a favourable pressure gradient. Usually, when the nozzles are under-expanded, the control is expected to become effective and increase base pressure. This phenomenon is seen when the area ratio of the duct is reduced to 3.24. An increase in base pressure is seen for NPR values more than two even though the nozzle is marginally under-expanded. With a further increase in the NPR, a substantial increase in base pressure occurs.

\section{Numerical Methodology}

Figure 2 shows a diagram of a converging nozzle and tube with a rib. The flow control through the rib is having the $W$ (width) $=3 \mathrm{~mm}$, and $H$ (height) is changed from 1 to $3 \mathrm{~mm}$, as shown in Figure 2. The nozzle inlet is $15 \mathrm{~mm}$ in radius, and the exit is $5 \mathrm{~mm}$ in radius. The duct size is $108 \mathrm{~mm}$. The internal duct radius is $9 \mathrm{~mm}$, with 3.24 as the area ratio. The flow is considered turbulent due to the occurrence of high Mach number. Thus, the $k-\varepsilon$ turbulence model is used. The flow equations represent the turbulent flow field most appropriately. The continuity equation for the compressible flow (density $\rho$ based) with the steady-state condition in the 2-dimensional cylindrical coordinate system is

$\frac{1}{r} \frac{\partial(\rho r u)}{\partial r}+\frac{\partial(\rho v)}{\partial z}=0$

The time-averaged axial $z$-momentum equation representing $u$ velocity of flow is given by

$$
\frac{1}{r} \frac{\partial(\rho r u u)}{\partial z}+\frac{1}{r} \frac{\partial(\rho v u)}{\partial r}=-\frac{\partial p}{\partial r}+\left(\mu+\mu_{t}\right) \frac{\partial}{\partial z}\left[2 \frac{\partial u}{\partial z}-\frac{2}{3}(\nabla \cdot \vec{v})\right]+\left(\mu+\mu_{t}\right) \frac{\partial}{\partial r}\left[\frac{\partial u}{\partial r}+\frac{\partial v}{\partial z}\right]
$$

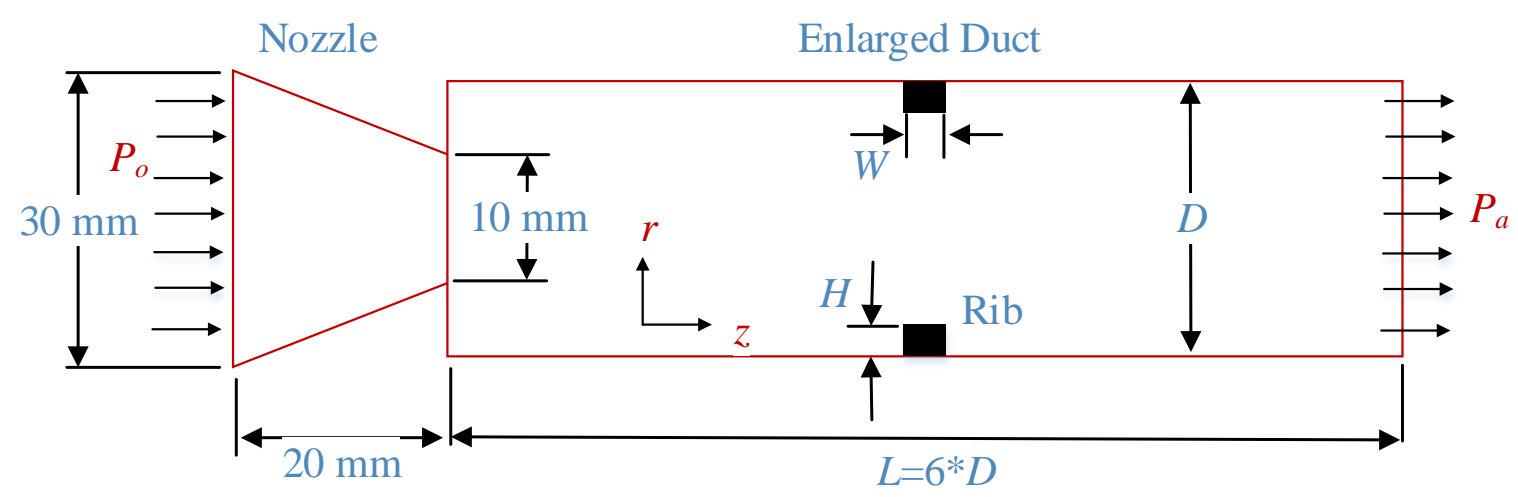

Fig. 2. Arrangement of nozzle and tube with rib 
The radial $r$-momentum equation for $v$ velocity is

$$
\begin{aligned}
& \frac{1}{r} \frac{\partial(\rho r u v)}{\partial z}+\frac{1}{r} \frac{\partial(\rho v v)}{\partial r}=-\frac{\partial p}{\partial r}+\left(\mu+\mu_{t}\right) \frac{\partial}{\partial r}\left[\left(2 \frac{\partial u}{\partial z}-\frac{2}{3}(\nabla \cdot \vec{v})\right)\right]+\left(\mu+\mu_{t}\right) \frac{\partial}{\partial z}\left[\left(\frac{\partial u}{\partial r}+\frac{\partial v}{\partial z}\right)\right]- \\
& 2 \frac{\left(\mu+\mu_{t}\right) v}{r^{2}}+\frac{2}{3} \frac{1}{r}\left(\mu+\mu_{t}\right)(\nabla \cdot \vec{v})
\end{aligned}
$$

The term $\vec{v}$ in Eq. (2) and Eq. (3) is given by

$$
\nabla \cdot \vec{v}=\frac{\partial u}{\partial z}+\frac{\partial v}{\partial r}+\frac{v}{r}
$$

Here, $\mu$ is viscosity.

The $k-\varepsilon$ model is widely used. It offers economy, sturdiness and sufficient exactness for several types of flow conditions. The $k-\varepsilon$ turbulence model used in the study is made accessible by ANSYS Fluent software. The turbulent kinetic energy, i.e., the K-equation, is given by

$$
\frac{\partial(\rho u \mathrm{~K})}{\partial z}+\frac{1}{r} \frac{\partial(\rho v \mathrm{~K})}{\partial r}=\frac{\partial}{\partial z}\left[\left(\mu+\frac{\mu_{t}}{\sigma_{k}}\right) \frac{\partial \mathrm{K}}{\partial z}\right]+\frac{1}{r} \frac{\partial}{\partial r}\left[r\left(\mu+\frac{\mu_{t}}{\sigma_{k}}\right) \frac{\partial \mathrm{K}}{\partial r}\right]-\rho \varepsilon+G
$$

$\sigma_{k}$ is the turbulent Prandtl number for $\mathrm{K}, \varepsilon$ is turbulent kinetic energy dissipation rate, and $G$ is the turbulence generation term given by

$$
G=\mu_{t}\left(\frac{\partial u_{i}}{\partial x_{j}}+\frac{\partial u_{j}}{\partial x_{i}}\right) \frac{\partial u_{i}}{\partial x_{j}}-\frac{2}{3} k \delta_{i j} \frac{\partial u_{i}}{\partial x_{j}}
$$

The kinetic energy of turbulence dissipation, i.e., $\varepsilon$-the equation, is given by

$$
\frac{\partial(\rho u \varepsilon)}{\partial z}+\frac{1}{r} \frac{\partial(\rho v \varepsilon)}{\partial r}=\frac{\partial}{\partial z}\left[\left(\mu+\frac{\mu_{t}}{\sigma_{\varepsilon}}\right) \frac{\partial \varepsilon}{\partial z}\right]+\frac{1}{r} \frac{\partial}{\partial r}\left[r\left(\mu+\frac{\mu_{t}}{\sigma_{\varepsilon}}\right) \frac{\partial \varepsilon}{\partial r}\right]-C_{1} f_{1}\left(\frac{\varepsilon}{\mathrm{K}}\right) G-C_{2} f_{2}\left(\frac{\varepsilon^{2}}{\mathrm{~K}}\right)
$$

$\mu_{t}=\rho f_{\mu} C_{\mu} k^{2} / \varepsilon$ represents turbulent viscosity, and the values of $C_{\mu}, C_{1}, C_{2}, f_{\mu}, \sigma_{k}, \sigma_{\varepsilon}$ are all arbitrary constants. Using ANSYS Fluent, this set of turbulent equations is solved simultaneously for the compressible flow. The gas is considered a perfect gas. Iterations recur until the remainders are less than $10 \mathrm{e}^{-5}$. Grid sizes were several times changed to provide sufficient correctness with a conjunction. A grid size with nodes of approximately 48441 and element size of 47988 were used when a grid neutrality analysis was performed using three distinct element dimensions, as shown in Figure 3. 


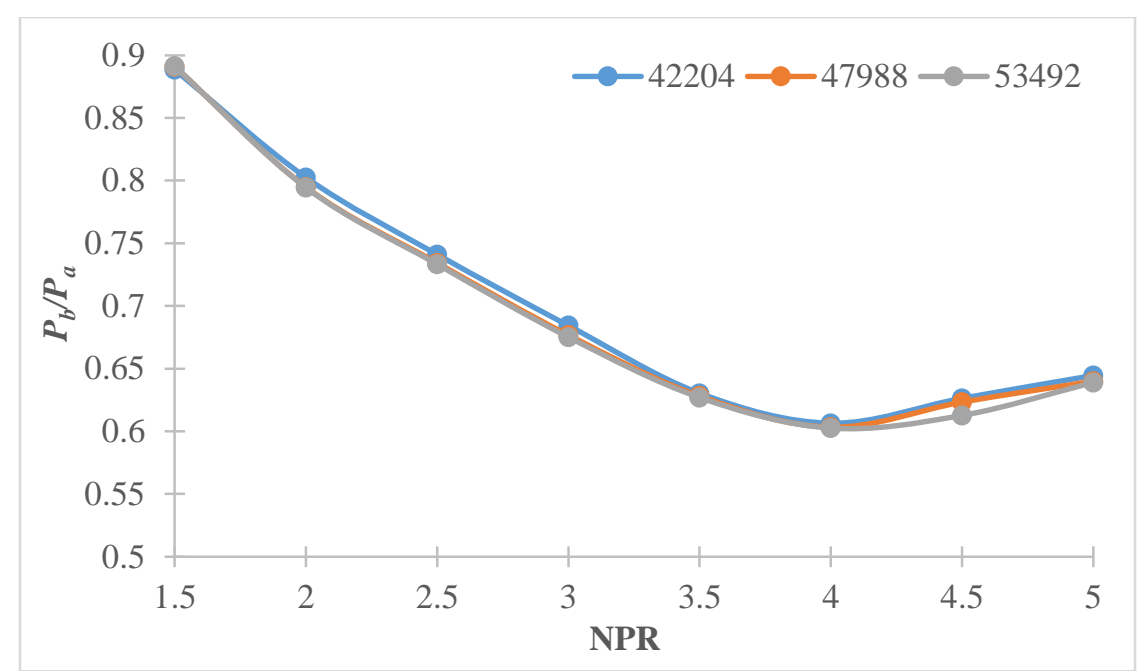

Fig. 3. Three distinct element sizes and converged values

To obtain and understand the proper physics of flow inside the duct given suddenly expanded flows with a single rib at different locations, the numerical ANSYS Fluent code is first validated with the results of Rathakrishnan [16]. They experimented with five ribs located at the central area in a duct, as demonstrated in Figure 4. The outcomes of base pressure deviation by various NPRs and L/D ratios are plotted in Rathakrishnan [16]. The work is validated to confirm the numerical findings, with and without ribs.

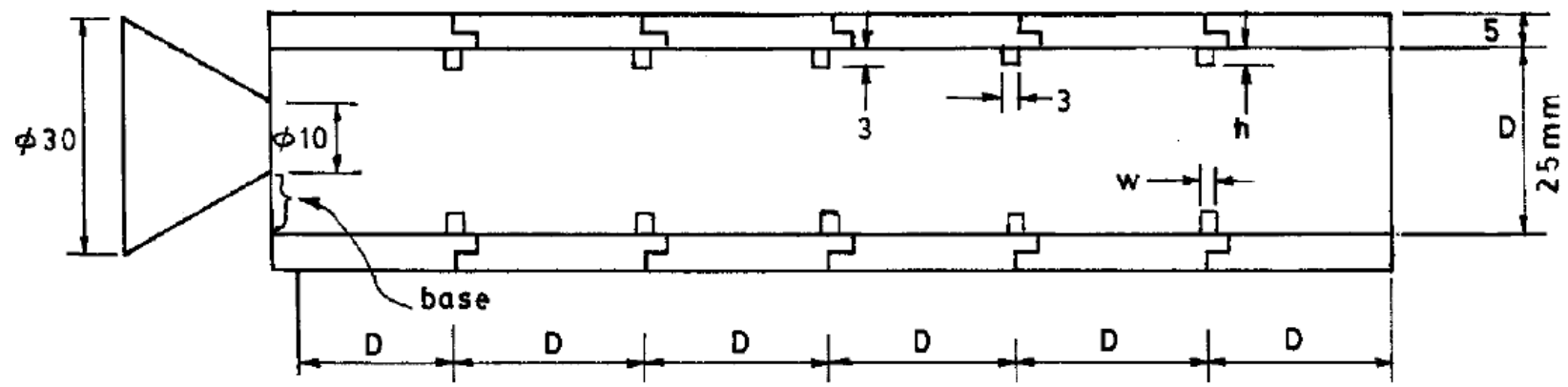

Fig. 4. View of the duct with five ribs used by Rathakrishnan [16] for experimental study

The base pressure variants acquired through an experiment and simulation using k- $\varepsilon$ model are matched in Figure 5. The nozzle running at Mach $M=1$ and NPR were used in the study. The outcomes show that the simulation results from the present study and wind tunnel values presented by Rathakrishnan [16] are in complete agreement. In their study, the duct had five ribs with aspect ratios of 3:1, 3:2 and 3:3. Insignificant base pressure results from the backflow's impact, and the boundary layer influences these duct sizes. 


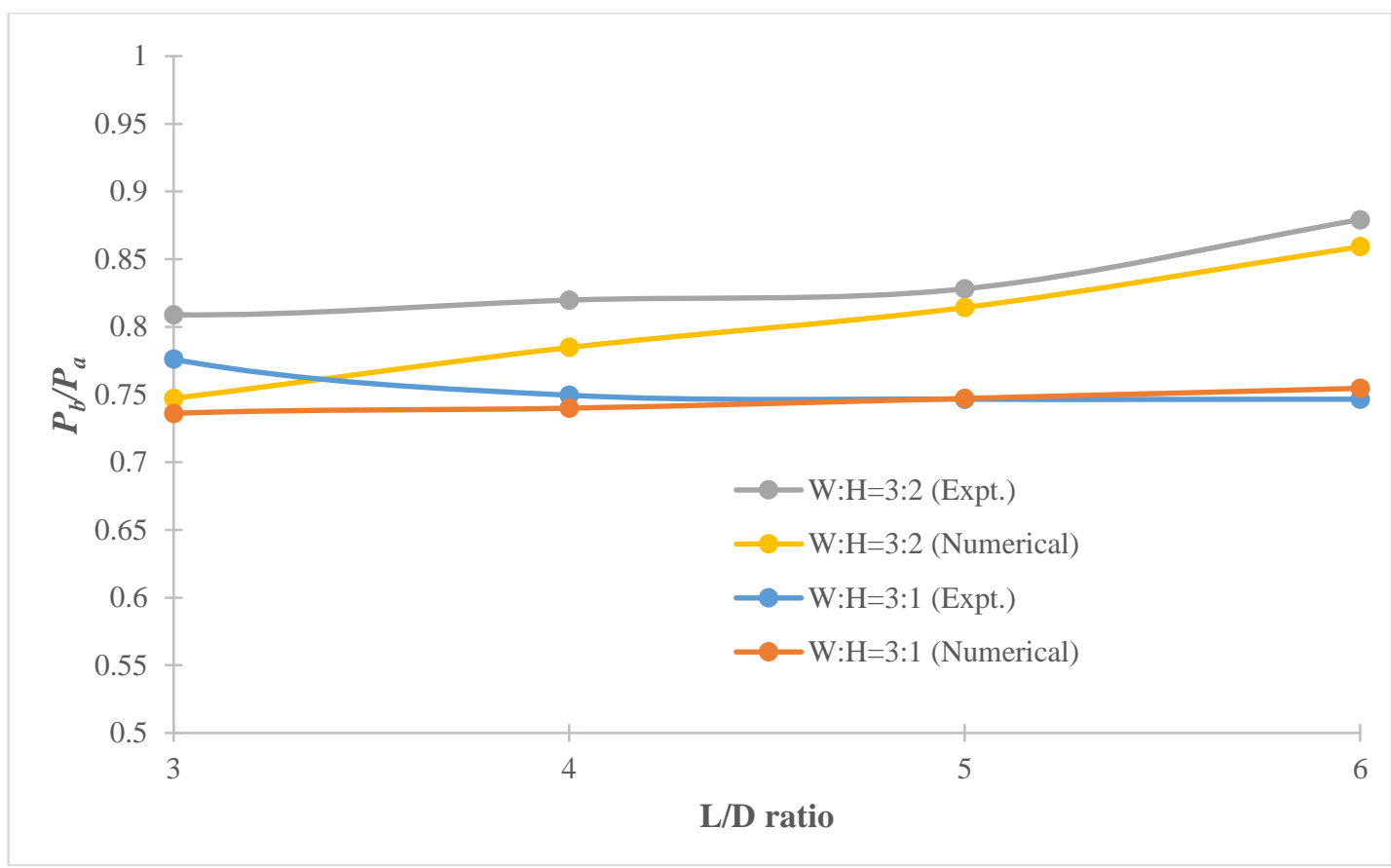

Fig. 5. Comparison of experimental and numerical outcomes

\section{Results and Discussions}

The numerical findings are considered. The radius of the duct, $r=9 \mathrm{~mm}$, and the duct size is 108 $\mathrm{mm}$. A different aspect ratio of the ribs and NPRs are discussed in detail. Base pressure deviations with NPRs ranging from 1.5 to 5 and ribs with aspect ratios of $3: 1$ to $3: 3$ are examined. The pressure for the 1D to 4D locations of ribs is examined in detail. Figure 6 depicts variation in base pressure obtained for the rib locations from 1D to 4D. One $D$ shifts the ribs from 3:1 to 3:3. The elevation is altered for every rib position, so the consequent enhancement or decline in base pressure obtained is mapped. The figure suggests that pressure in the recirculation zone rises as the rib location changes from 1D to 4D, regardless of aspect ratio. The behaviour of base pressure at different combinations is notable. The base pressure continues slightly increasing for other rib locations once the aspect ratio is $3: 1$ and 3:2. By contrast, for 3:3, a substantial enhancement occurs in the base pressure at 3D and $4 \mathrm{D}$. The difference is due to significant distractions produced in the stream by rib wherever the flow expands.

As mentioned, the locations of the rib are influential to the jet pump. Once the stream on or after the nozzle departs at great speed to the tube, the stream faces favourable or ideally expanded or adverse pressure, depending on the NPR. For the sonic Mach number the NPR needed is 1.89. However, the flow is unchoked for NPR less than 1.89. While the flow undergoes expansion as the NPR is more than 1.89. A shock is found at the nozzle exit for adverse pressure gradient. Under expansion, flow expansion occurs.

As explained, the mass being sucked into the dead zone at the corner is mainly disturbed, affecting the reattachment point. The fluid reversal from the reattachment point is severely affected if the flow finds the rib height in its path. At the 1D position, the reattachment point is ahead of the rib. Owing to suction at the base, the fluid reverses but faces the barriers. Thus, the base pressure decreases compared with the smooth duct. If the height of the rib is increased, flow reversal ultimately decreases, and base pressure decreases. The base pressure increases as the rib height increases to $3 \mathrm{~mm}$. The reason for this finding is that the shear layer exiting from the nozzle can find the rib corner even before reattaching itself with the duct wall. Additional fluid mass is forced to flow 
into the corner region, leading to the low intensity of the central vortex and the larger size of the ancillary vortex. Placing the rib may causes severe vibration due to flow disturbances. The reattachment point improves when ribs with different aspect ratios are placed at 2D and higher positions downstream. Such placement causes sufficient mass reversal and leads to improvement in base pressure.

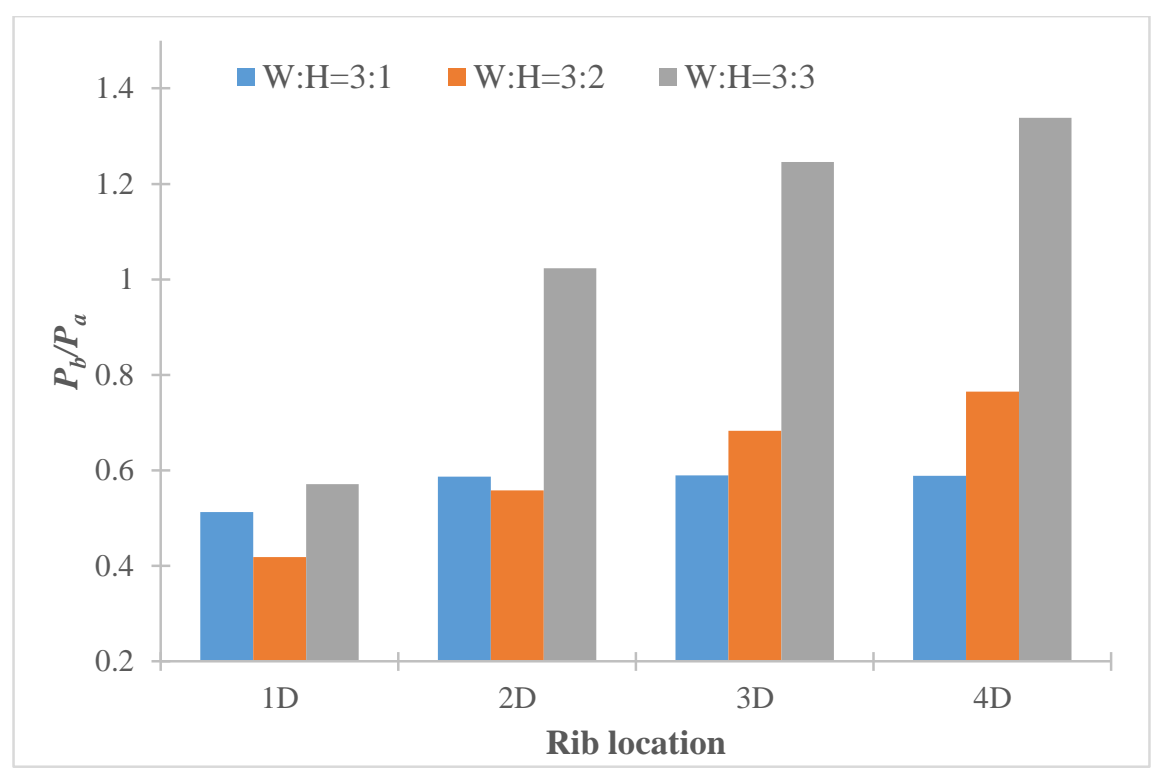

Fig. 6. Growth in base pressure by rib location and aspect ratio

The pressure distributes in the nozzle with no rib and a rib located at different distances after the base is shown in Figure 7. Once the stream inflates from the nozzle, the exiting flow experiences alternative firmness and extension due to the duct wall. Beyond this point, the nozzle of a compressed zone is observed, analogous to the diamond developed axially. Soon afterwards, they fade away as the stream moves lengthwise; this case occurs is when the duct has no rib. When a rib is positioned along the circumference down to the duct, the compressed zone becomes clearer. The rib location is shifted progressively from 1D to 4D, and the space among the consecutive compressed zones decreases, indicating the effect of the rib. When $\mathrm{H}$ rises, the power in zones increases, illustrating the considerable effect of passive control in the form of ribs.

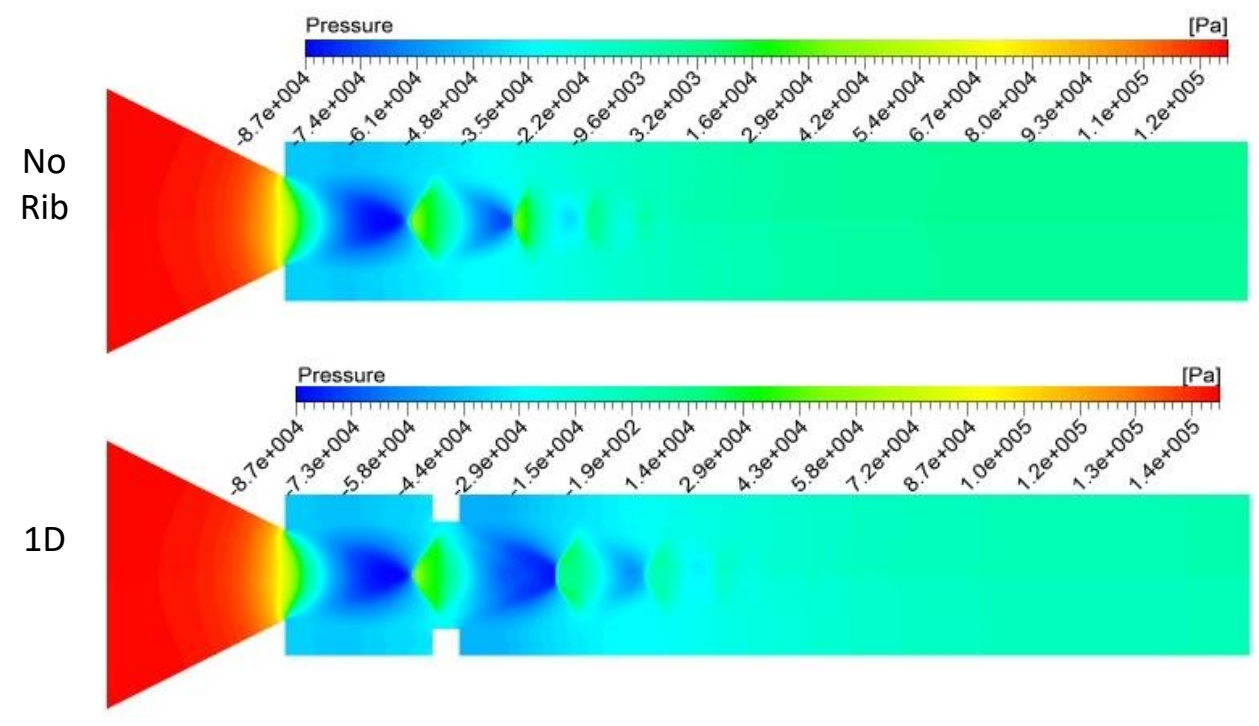




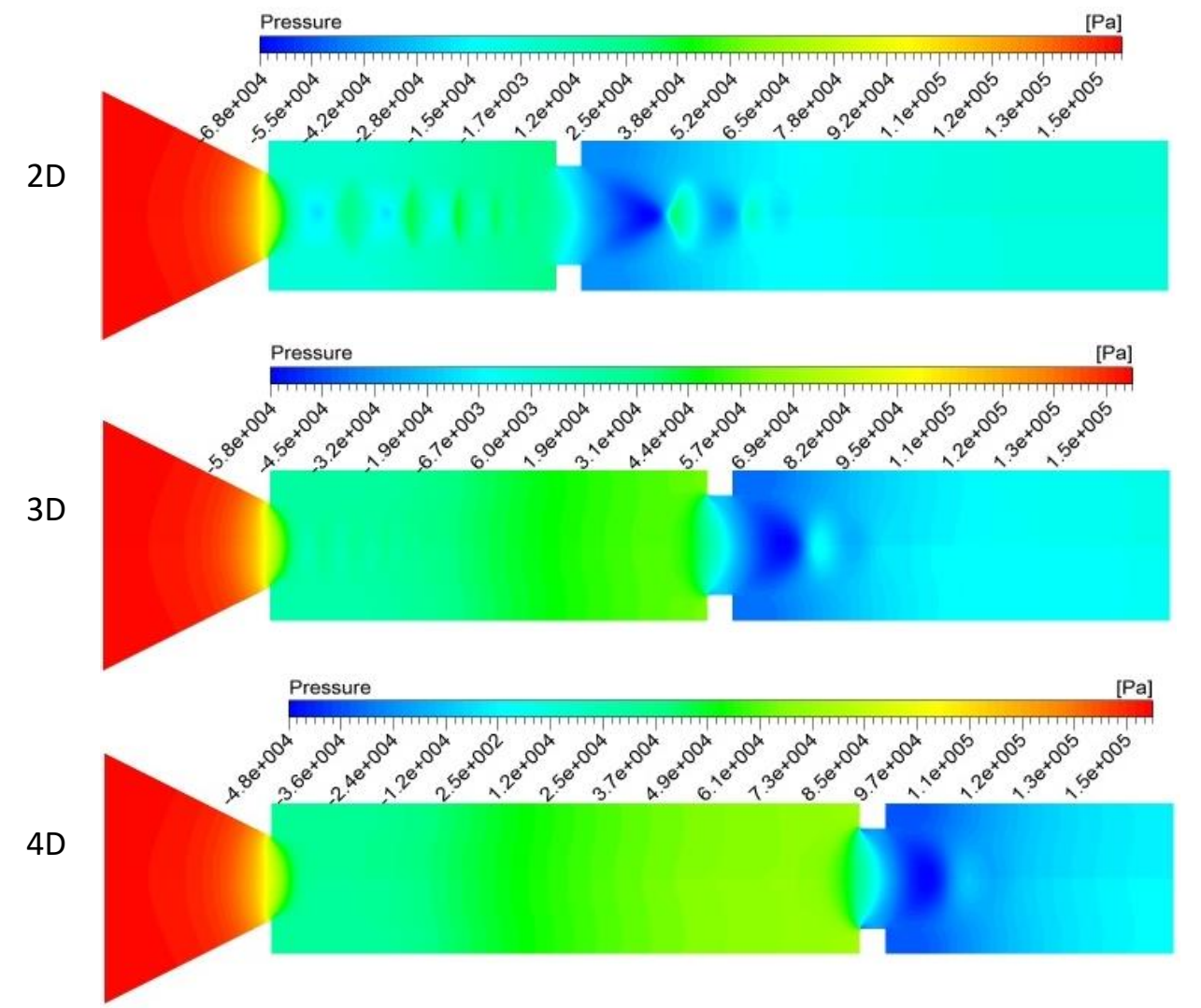

Fig. 7. Pressure variation at various rib positions holding for 3:3 aspect ratio

Figure 8 shows the velocity distribution in the entire duct. The contours are shown with and without rib with an aspect ratio of 3:3 placed at different positions. The rib location varies from 1D to 4D, with a fixed NPR of 2.5. The region of compression in advance of the nozzle exit is considerable. For positions $2 \mathrm{D}$ to $4 \mathrm{D}$, the ribs are in a shorter compression zone due to fluid hitting the wall. The more compressed the zones, the lower the speed and the lower the base pressure; the reduced distance among the ribs indicates lower velocity and higher pressure. The velocity dissemination of a duct with a rib needing a 3:3 aspect ratio is much brighter and describes its effect, as shown in Figure 8.

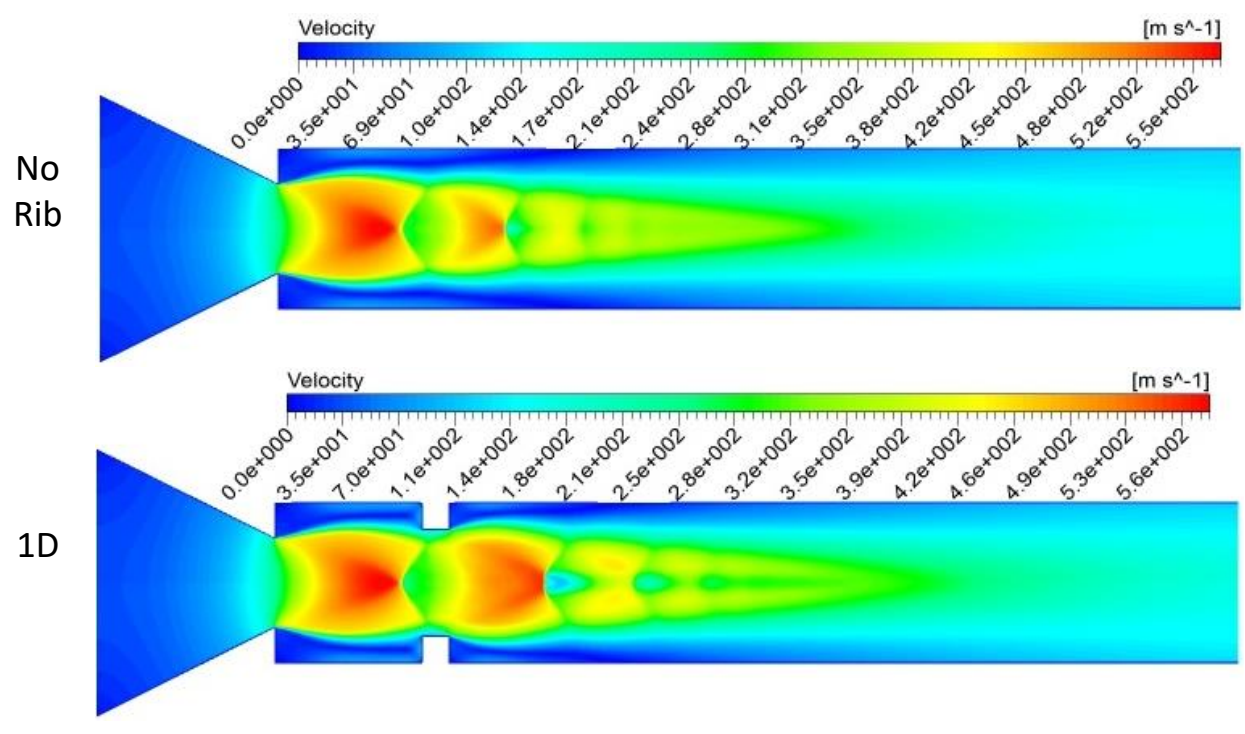




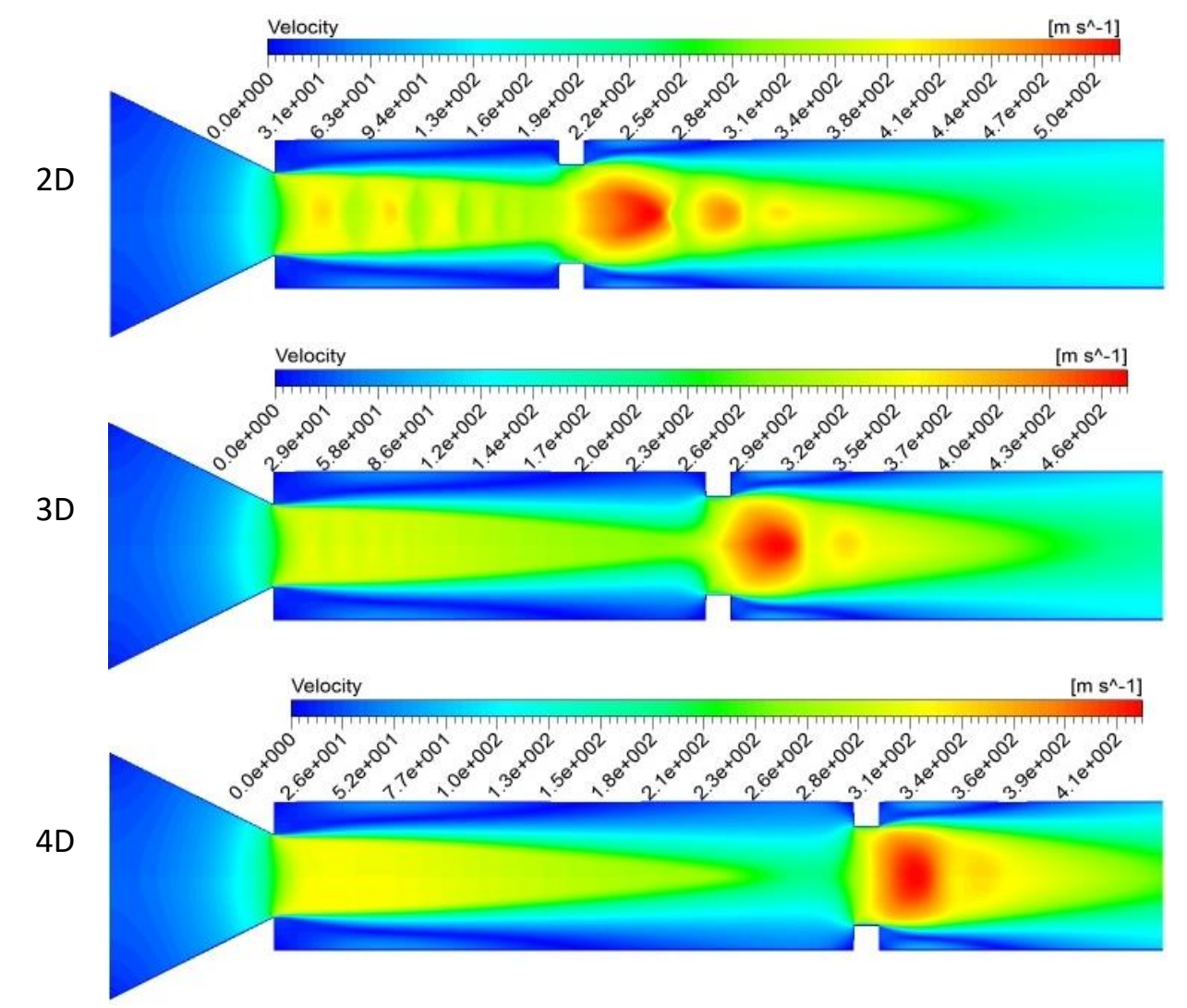

Fig. 8. Velocity dissemination for various rib locations for $3: 3$ aspect ratio rib

The influence of NPR on the pressure at the base area of the duct is presented in Figure 9. Here, the stream expands from the sonic Mach nozzle. NPR is raised from 1.5 to 5 at a distinct rib position from 2D to 4D with a fixed aspect ratio of 3:3. The ducts with ribs and no ribs are compared. Figure 9 indicates that the base pressure constantly declines for NPRs, varying in the range from 1.5 to 5 in the duct without passive control, whereas for ducts having passive control, the base pressure increases at various NPR. When the rib is fixed at the 2D location, the growth in base pressure is severe and consistently increases compared with the duct having no rib. For 3D and 4D rib locations, the base pressure rises slowly until NPR $=2$. As NPR increase, the stream expands more briskly with various levels of expansion, causing the shear layer to move a vast space before it attaches to the wall.

Consequently, the intensity of turbulent kinetic energy indulgence and influence of viscosity of the stream is minimal. Owing to the extra distance moved by the shear layer, the prime vortex volume increases and a smaller quantity of fluid undergoes turnaround, thereby regularly decreasing the base pressure. With a single rib, even with the lowest height of $1 \mathrm{~mm}$, the flow is affected, but instead of reduction, it remains nearly the same because the expansion fan is at the nozzle exit. The flow with the expansion level helps the rib affect the reattachment point for a further rise in rib location. When the rib location is at 3D and 4D, the base pressure increment is nearly the same, indicating that a minimal difference in base pressure if the rib is placed at 5D. The maximum variation in base pressure is seen at a 2D location only having a 3:3 aspect ratio. If the smaller aspect ratio rib is used, a base change would be surprising. 


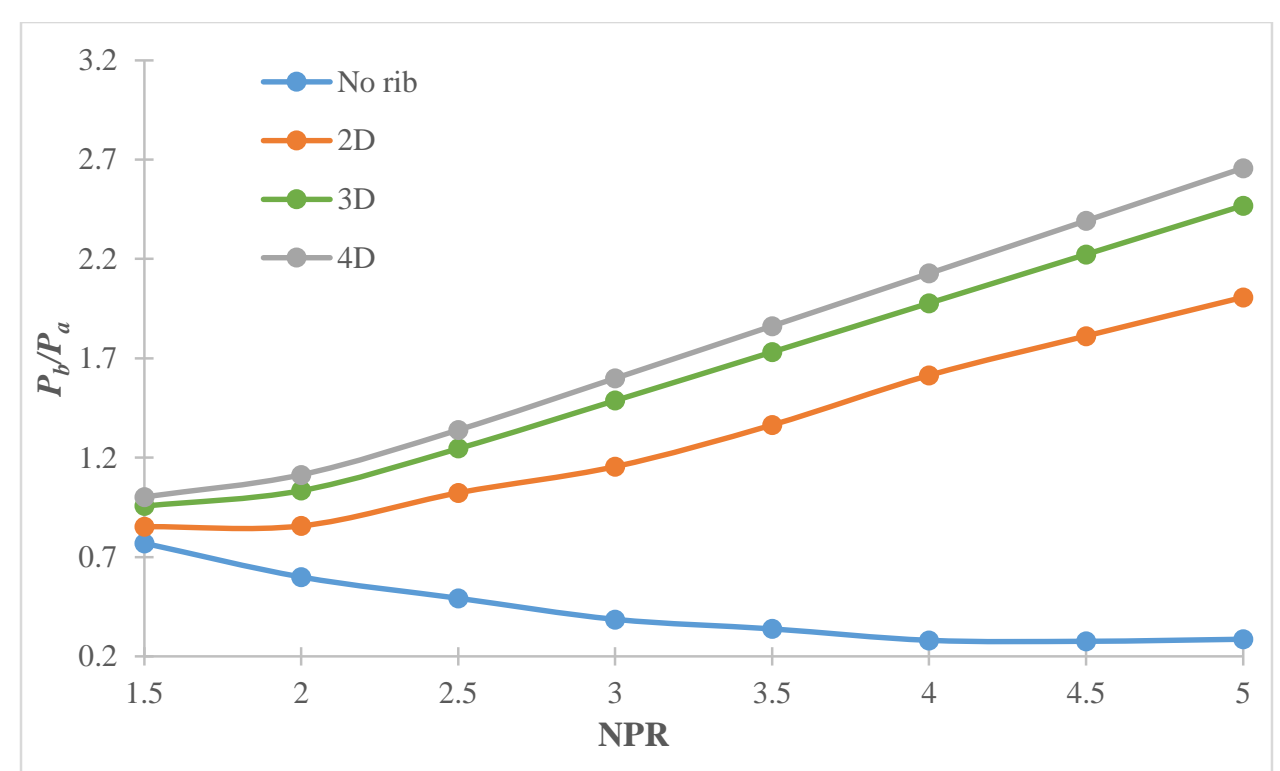

Fig. 9. Variation in the base pressure with NPR and rib location from 2D to 4D

The velocity variation along the duct length for various NPR is provided in Figure 10 . The aspect ratio chosen for the demonstration is $3: 3$ and NPR 1.5, 2.5, 3.5 and 4.5, where the intermediate NPRs are avoided for the sake of brevity. The location of the rib is fixed in this analysis at 2D as massive fluctuations in velocity pattern are obtained compared with the duct with no rib. At NPR 1.5, the flow velocity is relatively smooth when it expands in the duct. At NPR 2.5, the flow velocity has different patterns, and at the throat of the rib, the velocity is very high, causing a different flow shape compared with the duct with no rib. At higher NPR, the flow downstream of the rib is severely changed. The flow pattern is usually at the exit of the nozzle, but due to the rib with a 3:3 aspect ratio, this pattern is seen at the rib exit. The influence of rib's geometry on the changes of flow characteristics are consistent with the observation obtained in Sahak et al., [18] who observed the variation of flow regime with the cavity geometry.

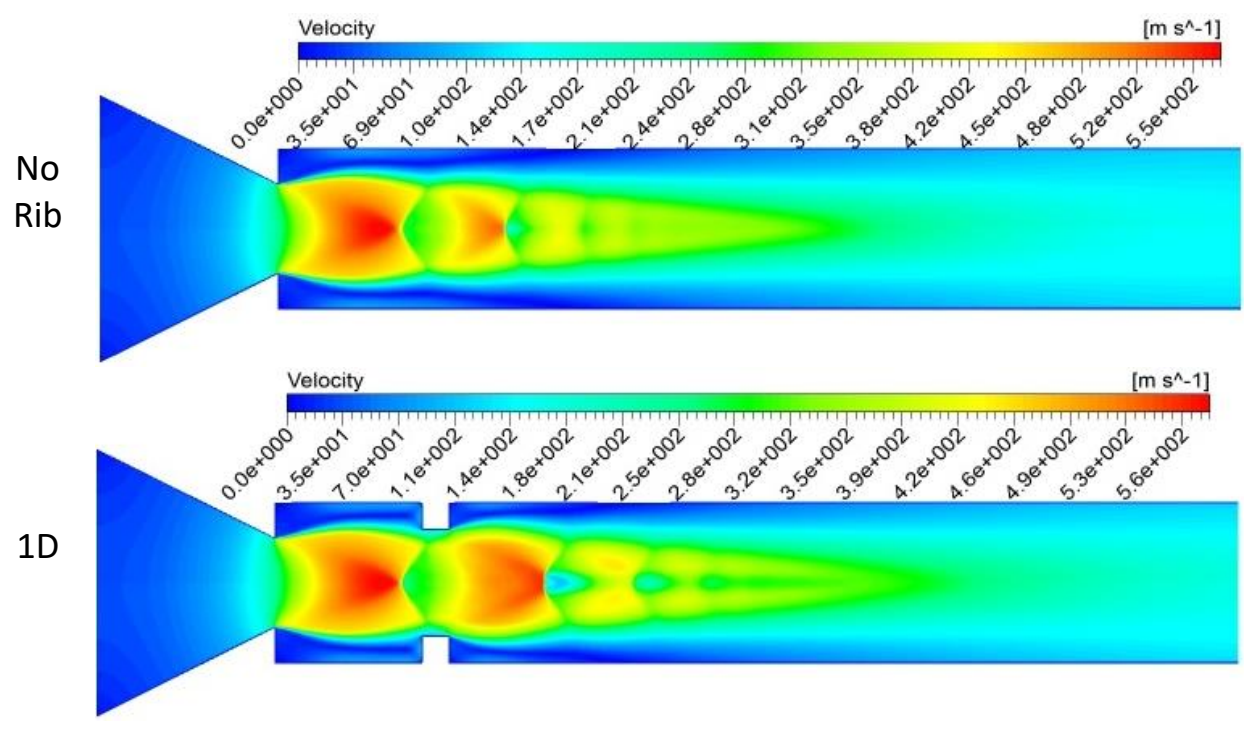




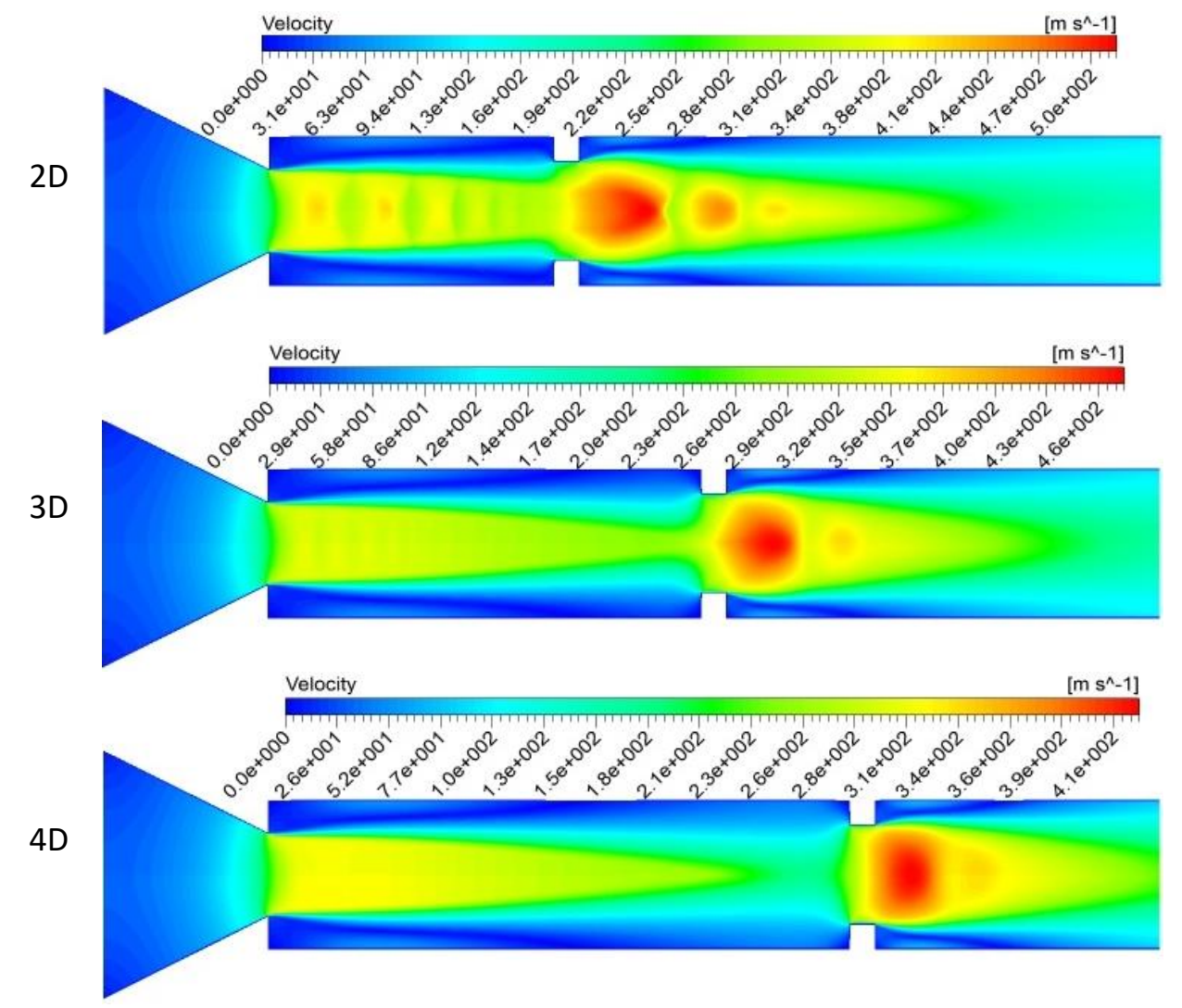

Fig. 10. Velocity in the duct with $3: 3$ rib at different NPR

\section{Conclusions}

The effect of a single rib located at different distances from the duct base is investigated numerically. The nozzle operates at a sonic Mach number, and the tube radius is $9 \mathrm{~mm}$, and the duct is six times the length of its diameter. The flow analysis using $k-\varepsilon$ turbulence modelling via ANSYS software reveals several phenomena. The presence of the rib considerably affects the base pressure and velocity in the duct. The aspect ratio of the rib is an indispensable aspect in increasing the base pressure. The base pressure starts increasing from NPR 2 and above. The 3D and 4D locations of the duct and higher aspect ratio of the rib have the maximum effect on pressure at the base region. The pressure in the base area increases at all NPR compared with the duct having no rib. The maximum base pressure increment was obtained at the highest NPR and a maximum rib height.

\section{Acknowledgements}

Acknowledgement to Ministry of Higher Education Malaysia for Fundamental Research Grant Scheme with Project Code: FRGS/1/2019/TK07/USM/03/5.

\section{References}

[1] Khan, Sher Afghan, and Ethirajan Rathakrishnan. "Active control of suddenly expanded flows from overexpanded nozzles." International Journal of Turbo and Jet Engines 19, no. 1-2 (2002): 119-126. https://doi.org/10.1515/TJJ.2002.19.1-2.119

[2] Khan, Sher Afghan, and Ethirajan Rathakrishnan. "Control of suddenly expanded flows with micro-jets." International Journal of Turbo and Jet Engines 20, no. 1 (2003): 63-82. https://doi.org/10.1515/TJJ.2003.20.1.63

[3] Khan, Ambareen, Abdul Aabid, and Sher Afghan Khan. "CFD analysis of convergentdivergent nozzle flow and base pressure control using micro-JETS." International Journal of Engineering and Technology 7, no. 3.29 (2018): 232235. https://doi.org/10.14419/ijet.v7i3.29.18802 
[4] Pathan, Khizar Ahmed, Prakash S. Dabeer, and Sher Afghan Khan. "Effect of nozzle pressure ratio and control jets location to control base pressure in suddenly expanded flows." Journal of Applied Fluid Mechanics 12, no. 4 (2019): 1127-1135. https://doi.org/10.29252/jafm.12.04.29495

[5] Pathan, Khizar Ahmed, Prakash S. Dabeer, and Sher Afghan Khan. "An investigation to control base pressure in suddenly expanded flows." International Review of Aerospace Engineering (IREASE) 11, no. 4 (2018): 162-169. https://doi.org/10.15866/irease.v11i4.14675

[6] Pathan, Khizar Ahmed, Sher Afghan Khan, and P. S. Dabeer. "CFD analysis of effect of area ratio on suddenly expanded flows." In 2017 2nd International Conference for Convergence in Technology (I2CT), pp. 1192-1198. IEEE, 2017. https://doi.org/10.1109/I2CT.2017.8226315

[7] Pathan, Khizar Ahmed, Sher Afghan Khan, and P. S. Dabeer. "CFD analysis of effect of flow and geometry parameters on thrust force created by flow from nozzle." In 2017 2nd International Conference for Convergence in Technology (I2CT), pp. 1121-1125. IEEE, 2017. https://doi.org/10.1109/I2CT.2017.8226302

[8] Pathan, Khizar Ahmed, Sher Afghan Khan, and P. S. Dabeer. "CFD analysis of effect of Mach number, area ratio and nozzle pressure ratio on velocity for suddenly expanded flows." In 2017 2nd International Conference for Convergence in Technology (I2CT), pp. 1104-1110. IEEE, 2017. https://doi.org/10.1109/I2CT.2017.8226299

[9] Vikramaditya, N. S., M. Viji, S. B. Verma, Naveed Ali, and D. N. Thakur. "Base pressure fluctuations on typical missile configuration in presence of base cavity." Journal of Spacecraft and Rockets 55, no. 2 (2018): 335-345. https://doi.org/10.2514/1.A33926

[10] Quadros, Jaimon Dennis, Sher Afghan Khan, and A. J. Antony. "Base pressure behaviour in a suddenly expanded duct at supersonic Mach number regimes using Taguchi design of experiments." Mechanics and Mechanical Engineering 22, no. 4 (2018): 1077-1097. https://doi.org/10.2478/mme-2018-0085

[11] Pathan, Khizar Ahmed, Prakash S. Dabeer, and Sher Afghan Khan. "Optimization of area ratio and thrust in suddenly expanded flow at supersonic Mach numbers." Case Studies in Thermal Engineering 12 (2018): 696-700. https://doi.org/10.1016/i.csite.2018.09.006

[12] Chaudhary, Zakir Ilahi, Vilas B. Shinde, Musavir Bashir, and Sher Afghan Khan. "Experimental Investigation on the Effectiveness of Active Control Mechanism on Base Pressure at Low Supersonic Mach Numbers." In Innovative Design and Development Practices in Aerospace and Automotive Engineering, pp. 197-209. Springer, Singapore, 2017. https://doi.org/10.1007/978-981-10-1771-1 24

[13] Khan, Sher Afghan, Abdul Aabid, and Maughal Ahmed Ali Baig. "CFD analysis of CD nozzle and effect of nozzle pressure ratio on pressure and velocity for suddenly expanded flows." International Journal of Mechanical and Production Engineering Research and Development 8, no. 3 (2018): 1147-1158. https://doi.org/10.24247/ijmperdjun2018119

[14] Khan, Sher Afghan, Zakir llahi Chaudhary, Maughal Ahmed Ali Baig, Hamza Afser Delvi, and Mohammed Faheem. "Impact of Mach number on the flow pattern in suddenly expanded duct." Materials Today: Proceedings (2021). https://doi.org/10.1016/i.matpr.2021.06.149

[15] Rehman, Shafiqur, and Sher Afghan Khan. "Control of base pressure with micro-jets: part I." Aircraft Engineering and Aerospace Technology (2008). https://doi.org/10.1108/00022660810859373

[16] Rathakrishnan, E. "Effect of ribs on suddenly expanded flows." AlAA Journal 39, no. 7 (2001): 1402-1404. https://doi.org/10.2514/2.1461

[17] Khan, Sher Afghan, and E. Rathakrishnan. "Control of suddenly expanded flow." Aircraft Engineering and Aerospace Technology (2006). https://doi.org/10.1108/17488840610675573

[18] Sahak, Ahmad Sofianuddin A., Nor Azwadi Che Sidik, and Siti Nurul Akmal Yusof. "A Brief Review of Particle Dispersion of Cavity Flow." Journal of Advanced Research in Applied Sciences and Engineering Technology 20, no. 1 (2020): 27-41. https://doi.org/10.37934/araset.20.1.2741 